\title{
VOLTAGE STABILITY ANALYSIS BASED ON ENERGY FUNCTION OF AN ELECTRICAL POWER SYSTEM WITH AND WITHOUT SVC
}

\author{
Ahmet Çifci, Yılmaz Uyaroğlu
}

Preliminary notes

This paper presents a study based on the variable gradient method for the construction of a Lyapunov (energy) function. The single-machine infinite-bus (SMIB) power system with and without static VAR compensator (SVC) is considered. Voltage stability analysis is studied on both power systems. The performance of SVC on voltage stability of the system is shown and numerical simulations are compared with each other. Additionally, it is demonstrated that the stored energy density is an indicator of the closeness of the operating point to the instability region of the system. The simulation results for the studied models are obtained by using MATHCAD software.

Keywords: Lyapunov (energy) function; single-machine infinite-bus power system; static VAR compensator; variable gradient method; voltage stability

\section{Analiza stabilnosti napona na temelju funkcije energije u elektroenergetskom sustavu sa i bez SVC}

Prethodno priopećenje

U ovom se radu opisuje analiza temeljena na metodi promjenjivog gradijenta za tvorbu Lyapunove funkcije (energije). Razmatra se energetski sustav neograničene sabirnice stroja - SMIB (Single Machine Infinite Bus) sa i bez statičkog VAR kompenzatora (SVC). Analiza stabilnosti napona provedena je na oba energetska sustava. Pokazan je rad SVC kod stabilnog napona sustava i numeričke su simulacije uspoređene jedna s drugom. Dodatno je pokazano da je gustoća pohranjene energije pokazatelj blizine točke u kojoj će doći do nestabilnosti sustava. Rezultati simulacije za analizirane modele dobiveni su primjenom MATHCAD softvera.

Ključne riječis: energetski sustav neograničene sabirnice stroja; Lyapunova funkcija (energije); metoda promjenjivog gradijenta; stabilnost napona; statički VAR kompenzator

\section{Introduction}

In recent years, the continued growth of power demand has led the electric power systems to become increasingly large and complex. That forces the power systems to be operated near their stability limits. On the other hand, the stability of electric power systems has received a great amount of attention in the literature. Voltage stability phenomenon has been recognized as one of the biggest problems in power systems. Voltage stability is expressed as the ability of a power system to maintain steady voltage at all of the buses in the system after being subjected to a disturbance from a given initial operating condition [1].

The fast development of semiconductor power electronic devices has led to the application of Flexible Alternating Current Transmission Systems (FACTS). The FACTS devices are used to control voltages at critical buses, impedance of transmission lines and the phase angles between the ends of transmission lines. The voltage stability margin can be enhanced by the FACTS devices. Among the several FACTS devices, SVC is one of the most important and well-known FACTS devices for the effective enhancement of voltage stability. SVC can also compensate the reactive power in a power system to enhance the transient stability, reduce system losses and damp power swings. The voltage stability improvement in power systems using SVC has been studied by several authors and still is. Kasusky et al. [2] studied the effect of SVC on voltage collapse in a power system due to changes in the reactive power demand. SVC with washout filter-aided feedback is designed in [3] in order to stabilize the bifurcation and voltage collapse on a single generator infinite bus system with induction motor load. Liaw et al. [4] presented a different approach by the load voltage regulation design of a power system via the tuning of SVC. See also [5], where authors analysed the impact of SVC on bifurcations, chaos and voltage collapse in power systems. In [6], Blasina et al. investigated the characteristics and the effects of SVC devices as the origin of the FACTS devices, and their use in power systems. In addition, Komen et al. [7] discussed the impact of SVC on voltage circumstances and reactive power flows in a Croatian power system at low and high loads.

An electric power system is usually defined by nonlinear dynamical equations including system parameters. Any sort of change in any parameter of the system could affect the behaviour of nonlinear dynamical system. Hence, the system parameter variations can result in instability. Lyapunov stability theorems give sufficient conditions for stability. Lyapunov's second method or Lyapunov's direct method provides an important approach for the stability analysis of a system without solving differential equations. Lyapunov (energy) functions offer a certain estimate of the stability region. Nevertheless, there are no generally applicable methods for generating Lyapunov functions. Some approaches to generating Lyapunov functions are suitable. The variable gradient method is a formal approach to generating Lyapunov functions. The present paper deals with voltage stability analysis via the variable gradient method to provide a suitable candidate for Lyapunov (energy) function on a single-machine infinite-bus (SMIB) power system with and without SVC.

The structure of this paper is as follows: Section 2 presents the power system model with and without SVC used in this paper and the principles of design for SVC are explained. The main idea of the variable gradient method for constructing a suitable Lyapunov function is 
outlined in section 3. Furthermore, section 3 also presents the simulation results and analysis. Section 4 is devoted to the conclusions.

\section{Power system model}

The description of several power system models used in this study are as follows.

\subsection{The SMIB power system}

Consider the single machine infinite bus power system model as depicted in Fig. 1 [8].

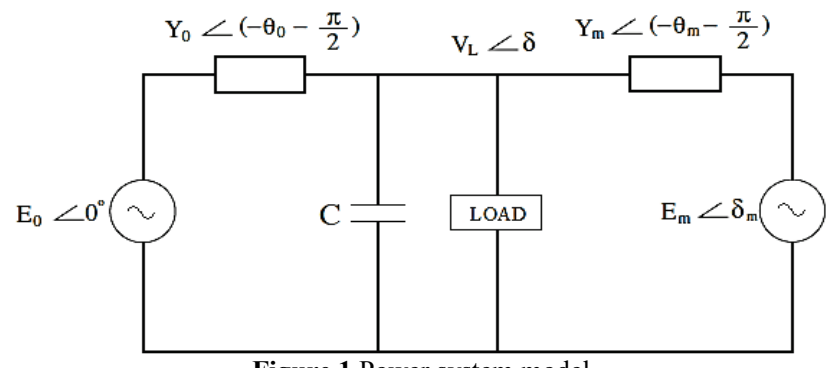

Figure 1 Power system model

It consists of a load bus and two generator buses. One of the generator buses is treated as a slack bus and the other generator is expressed by the swing equation:

$M \ddot{\delta}_{m}+D \dot{\delta}_{m}=P_{m}+E_{m} V Y_{m} \sin \left(\delta-\delta_{m}-\theta_{m}\right)+E_{m}{ }^{2} Y_{m} \sin \theta_{m}$,

where $M, D, P_{m}, E_{m}, V$ and $Y_{m}$ are generator inertia, damping coefficient, mechanical power, generator voltage, load voltage and generator admittance, respectively. Furthermore, $\delta_{m}, \delta$ and $\theta_{m}$ are generator rotor angle, load angle and generator admittance angle, respectively.

The load is modelled by a simplified induction motor in parallel with a constant $P-Q$ load and constant impedance. The load also includes a fixed capacitor, $C$, to raise the voltage up to near 1,0 per unit. The load dynamics model is expressed as follows:

$$
\begin{aligned}
& P_{d}=P_{0}+P_{1}+K_{p w} \dot{\delta}+K_{p v}(V+T \dot{V}), \\
& Q_{d}=Q_{0}+Q_{1}+K_{q w} \dot{\delta}+K_{q v} V+K_{q v 2} V^{2}
\end{aligned}
$$

where $P_{0}, Q_{0}$ and $P_{1}, Q_{1}$ are real and reactive power for induction motor and P-Q load, respectively. $K_{p w}, K_{p v}, K_{q w}$, $K_{q v}$ and $K_{q v 2}$ are constants associated to the dynamic load and accepted as fixed. $T$ is characteristic time constant. The active and reactive powers supplied to the load by the network are

$$
\begin{aligned}
& P=-E_{0}^{\prime} V Y_{0}^{\prime} \sin \left(\delta+\theta_{0}^{\prime}\right)-E_{m} V Y_{m} \sin \left(\delta-\delta_{m}+\theta_{m}\right)+ \\
& +\left(Y_{0}^{\prime} \sin \theta_{0}^{\prime}+Y_{m} \sin \theta_{m}\right) V^{2}, \\
& Q=E_{0}^{\prime} V Y_{0}^{\prime} \cos \left(\delta+\theta_{0}^{\prime}\right)+E_{m} V Y_{m} \cos \left(\delta-\delta_{m}+\theta_{m}\right)+ \\
& -\left(Y_{0}^{\prime} \cos \theta_{0}^{\prime}+Y_{m} \cos \theta_{m}\right) V^{2},
\end{aligned}
$$

where $E_{0}, Y_{0}$ and $\theta_{0}$ are infinite bus voltage, infinite bus admittance and infinite bus admittance angle, respectively.

The single-machine infinite-bus power system can be mathematically described by the following four ordinary differential equations:

$\dot{\delta}_{m}=\omega$,

$M \dot{\omega}=-D \omega+P_{m}+E_{m} V Y_{m} \sin \left(\delta-\delta_{m}-\theta_{m}\right)+$

$+E_{m}{ }^{2} Y_{m} \sin \theta_{m}$,

$K_{q w} \dot{\delta}=-K_{q v} V-K_{q v 2} V^{2}+Q-Q_{0}-Q_{1}$,

$T K_{q w} K_{p v} \dot{V}=K_{p w} K_{q v 2} V^{2}+\left(K_{p w} K_{q v}-K_{q w} K_{p v}\right) V+$

$+K_{p w}\left(Q_{0}+Q_{1}-Q\right)-K_{q w}\left(P_{0}+P_{1}-P\right)$,

where the variable $\omega$ is rotor speed.

\subsection{Static VAR compensator}

SVC is basically a shunt connected static VAR generator/load whose output is adjusted to exchange capacitive or inductive current to the system. So SVC controls the significant power system variables, in general the controlled variable is SVC bus voltage. A first order time delay model of SVC [2] is considered as shown in Fig. 2.

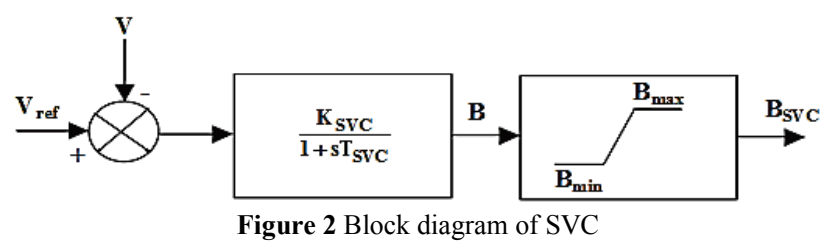

The equations describing the dynamics of SVC are as follows:

$$
\dot{B}=\frac{1}{T_{\mathrm{SVC}}}\left(K_{\mathrm{SVC}}\left(V_{\mathrm{ref}}-V\right)-B\right), B_{\min } \leq B \leq B_{\max },
$$

where $B$ is the susceptance of $\mathrm{SVC}, K_{\mathrm{SVC}}$ is $\mathrm{SVC}$ gain, $T_{\mathrm{SVC}}$ is the time constant of SVC and $V_{\text {ref }}$ is the reference voltage. SVC hard limiters are modelled by using tanh function. For a susceptance $B$ with limits $\pm B_{\text {LIMIT }}$, the output of the limiter is given by

$B_{\mathrm{SVC}}=B_{\text {LIMIT }} \tanh \left(\frac{B}{B_{\text {LIMIT }}}\right)$.

In addition, an additional reactive power $Q_{\mathrm{SvC}}$ that is added to the load reactive power is given as

$Q_{\mathrm{SVC}}=B V^{2}$

\subsection{The SMIB power system with SVC}

Consider the single machine infinite bus power system model with SVC as shown in Fig. 3. The studied SVC scheme consists of a fixed capacitor connected in parallel with a thyristor controlled reactor. The effective 
reactance of the controlled reactor is a function of the firing angle of the thyristor [3]. The node that voltage needs to be controlled should be connected with SVC. SVC is usually connected at the middle of a transmission line or at a load bus. In this study, SVC is connected in parallel to the load bus.

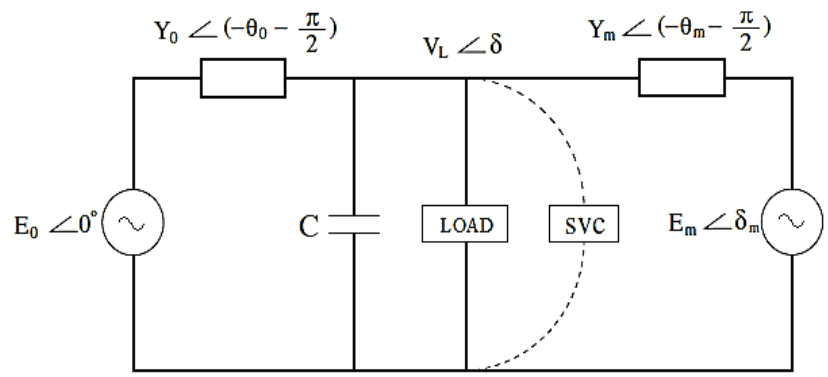

Figure 3 Power system model with SVC

The equations describing the dynamics of the singlemachine infinite-bus power system with SVC are as follows [5]:

$\dot{\delta}_{m}=\omega$

$M \dot{\omega}=-D \omega+P_{m}+E_{m} V Y_{m} \sin \left(\delta-\delta_{m}-\theta_{m}\right)+$

$+E_{m}{ }^{2} Y_{m} \sin \theta_{m}$,

$K_{q w} \dot{\delta}=-K_{q v} V-K_{q v 2} V^{2}+Q-Q_{0}+Q_{\mathrm{SVC}}-Q_{1}$,

$T K_{q w} K_{p v} \dot{V}=K_{p w} K_{q v 2} V^{2}+\left(K_{p w} K_{q v}-K_{q w} K_{p v}\right) V+$

$+K_{p w}\left(Q_{0}-Q_{\mathrm{SvC}}+Q_{1}-Q\right)-K_{q w}\left(P_{0}+P_{1}-P\right)$.

\section{Energy (Lyapunov) function analysis}

Energy functions are a specific form of Lyapunov functions. The application of energy functions to electric power systems has a long history and has been discussed by many authors (see, for example, $[9 \div 14]$ and references cited therein).

\subsection{The variable gradient method}

There are a number of methods devised for the construction of Lyapunov functions. Some approaches are Zubov's method [15], method of Szegö [16], method of Ingwerson [17] and Krasovskii's method [18]. Despite all these methods, Schultz and Gibson's variable gradient method [19] is one of the famous techniques for constructing a Lyapunov function. The method is very general and powerful because it provides considerable flexibility in selecting a suitable function. Furthermore, it provides more global conditions about the stability.This method is applicable to autonomous systems and often leads to a desired Lyapunov function for a given system.

This section continues by reviewing the usual variable gradient method $[19 \div 21]$. Consider the nonlinear system

$\dot{x}=f(x, t)$.

Denote a test Lyapunov function by using $V$ and its time derivative $\dot{V}$. In (17), $\mathrm{V}$ is $x$ 's open function but not $t$ 's.

$$
\dot{V}=\frac{\partial V}{\partial x_{1}} \frac{\mathrm{d} x_{1}}{\mathrm{~d} t}+\frac{\partial V}{\partial x_{2}} \frac{\mathrm{d} x_{2}}{\mathrm{~d} t}+\ldots+\frac{\partial V}{\partial x_{n}} \frac{\mathrm{d} x_{n}}{\mathrm{~d} t}
$$

Denoted in terms of the gradient, Eq. (18) can be written as:

$\dot{V}=(\nabla V)^{*} \dot{x}$

where $(\nabla V)^{*}$ is the transpose of $\nabla V . V$ is obtained as a line integral of $\nabla V$, as:

$$
V=\int_{0}^{x}(\nabla V)^{*} \mathrm{~d} x .
$$

The integral's upper limit here does not point that $V$ is a vector quantity, but integral is preferred to line integral of a random point $\left(x_{1}, x_{2}, \ldots, x_{n}\right)$ at the phase-space. This integral can be made independent of integration method.

Consider a gradient system of the form [22]

$$
\dot{x}=-A \nabla V\left(x, x_{0}\right)
$$

where $V: \mathfrak{R}^{n} \times \mathfrak{R}^{n} \rightarrow \mathfrak{R}$ is a continuously differentiable function, $A \in \mathfrak{R}^{n \times n}, \operatorname{det}(A) \neq 0$ and $V\left(x, x_{0}\right)=0$ at $x=x_{0}$. If the Hessian of $V\left(x, x_{0}\right)$ is completely positive definite at $x_{0}$, the equilibrium point is asymptotically stable at $x_{0}$. Lyapunov (energy) function is given as:

$$
V(x)=\int_{x_{0}}^{x}[f(\xi)]^{\mathrm{T}} \mathrm{d} \xi .
$$

The Eq. (22) will be used in order to construct a suitable candidate Lyapunov function of the singlemachine infinite-bus power system with and without SVC.

\subsection{Energy function of the SMIB power system and numerical simulations}

The single-machine infinite-bus power system model differential equations above can be written again under the condition that the generator mechanical power is equivalent to the active load requirement $\left(P_{m}=P_{1}\right)$.

$$
\begin{aligned}
& \dot{\omega}=-\frac{D}{M^{2}} M \omega-\frac{1}{M} a\left(\delta, \delta_{m}, V\right), \\
& \dot{\delta}_{m}=\frac{1}{M} M \omega \\
& \dot{\delta}=-b\left(\delta, \delta_{m}, V\right) \\
& \dot{V}=-c\left(\delta, \delta_{m}, V\right)
\end{aligned}
$$

where,

$a\left(\delta, \delta_{m}, V\right)=-\left[P_{m}+E_{m} V Y_{m} \sin \left(\delta-\delta_{m}-\theta_{m}\right)+E_{m}{ }^{2} Y_{m} \sin \left(\theta_{m}\right)\right]$, 


$$
\begin{aligned}
& b\left(\delta, \delta_{m}, V\right)=-\frac{1}{K_{q w}}\left(-K_{q v 2} V^{2}-K_{q v} V+Q-Q_{0}-Q_{1}\right), \\
& c\left(\delta, \delta_{m}, V\right)=-\frac{1}{T K_{q w} K_{p v}}\left[K_{p w} K_{q v 2} V^{2}+\left(K_{p w} K q v \ldots-\right.\right. \\
& \left.\left.-K_{q w} K_{p v}\right) V+K_{p w}\left(Q_{0}+Q_{1}-Q\right)-K_{q w}\left(P_{0}+P_{1}-P\right)\right] .
\end{aligned}
$$

The derivation of Lyapunov function for the singlemachine infinite-bus power system, Eqs. (23), (24), (25) and (26) could be determined as:

$$
\left[\begin{array}{c}
\dot{\delta}_{m} \\
\dot{\omega} \\
\dot{\delta} \\
\dot{V}
\end{array}\right]=\left[\begin{array}{cccc}
0 & -\frac{1}{M} & 0 & 0 \\
\frac{1}{M} & \frac{D}{M^{2}} & 0 & 0 \\
0 & 0 & 1 & 0 \\
0 & 0 & 0 & 1
\end{array}\right]\left[\begin{array}{c}
a\left(\delta_{m}, \delta, V\right) \\
M \omega \\
b\left(\delta_{m}, \delta, V\right) \\
c\left(\delta_{m}, \delta, V\right)
\end{array}\right] .
$$

Eq. (30) for the model defined in Eqs. (6), (7), (8) and (9) is an alternative definition for dynamics of this model. For the $\left(\omega_{0}, \delta_{m 0}, \delta_{0}, V_{0}\right)$ 's equilibrium point, a candidate energy function, which is seen on the right of Eq. (30), $((4 \times 1)$ gradient matrix seen on the right of Eq. (30)) is obtained and therefore it can be used in Eq. (22). The candidate energy function can be written in Eq. (22) as:

$$
v\left(\omega, \delta_{m}, \delta, V\right)=\int_{\left(\omega_{0}, \delta_{m 0}, \delta_{0}, V_{0}\right)}^{\left(\omega, \delta_{m}, \delta, V\right)}\left[\begin{array}{c}
M \omega \\
a\left(\delta_{m}, \delta, V\right) \\
b\left(\delta_{m}, \delta, V\right) \\
c\left(\delta_{m}, \delta, V\right)
\end{array}\right]^{\mathrm{T}}\left[\begin{array}{c}
\mathrm{d} \omega \\
\mathrm{d} \delta_{m} \\
\mathrm{~d} \delta \\
\mathrm{d} V
\end{array}\right] .
$$

If $a\left(\omega, \delta_{m}, \delta, V\right), b\left(\omega, \delta_{m}, \delta, V\right)$ and $c\left(\omega, \delta_{m}, \delta, V\right)$ are replaced on Eq. (31), energy function of the singlemachine infinite-bus power system is obtained [23]. The equilibrium point is $\left(\omega^{*}, \delta_{m}{ }^{*}, \delta^{*}, V^{*}\right)=(0,0 ; 0,7855 ; 0,2 ; 1)$.

The generator rotor angle will be changed, beginning with zero and will be increased to 1,6 by 0,4 rise each turn in order to observe the system stability. The numerical simulations of the single-machine infinite-bus power system are carried out by using Mathcad [24].

The energy density of the studied system is in the range of $0,6 \leq V \leq 1$ and $1 \leq \delta \leq 1,6$, which is seen as in Fig. 4 and Tab. 1. The energy density of the studied system varies between 9,2 and 11 energy units around these points.

The numerical values of the energy function for different load angles and different load voltages for $\delta_{\mathrm{m}}=0$ rad are shown in Tab. 1.

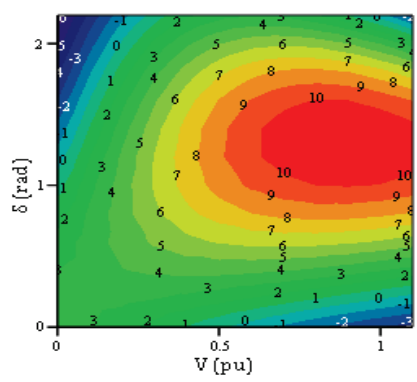

(a)

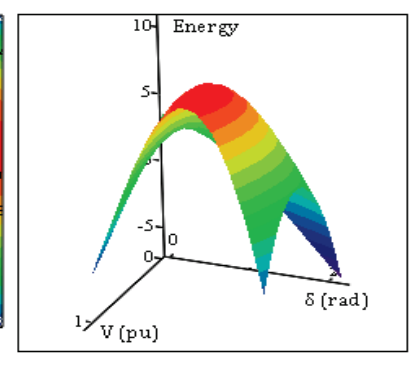

(b)
Figure 4 Stored energy for $\delta_{m}=0$ : (a) plot of the contours (b) 3D of the studied model
Table 1 Energy measurement for $\delta_{m}=0$

\begin{tabular}{|c|c|c|c|c|c|c|c|c|c|c|c|}
\hline$\delta$ & \multicolumn{10}{|c|}{ Energy measurement } \\
\hline 0 & 3,7 & 3,1 & 2,4 & 1,7 & 1,0 & 0,2 & $-0,5$ & $-1,2$ & $-1,8$ & $-2,4$ & $-3,0$ \\
\hline 0,2 & 3,4 & 3,4 & 3,3 & 3,0 & 2,7 & 2,4 & 2,0 & 1,5 & 1,0 & 0,5 & 0,0 \\
\hline 0,4 & 3,0 & 3,6 & 4,0 & 4,2 & 4,4 & 4,4 & 4,3 & 4,1 & 3,8 & 3,5 & 3,1 \\
\hline 0,6 & 2,4 & 3,5 & 4,4 & 5,2 & 5,7 & 6,1 & 6,3 & 6,4 & 6,3 & 6,2 & 5,9 \\
\hline 0,8 & 1,5 & 3,2 & 4,6 & 5,8 & 6,8 & 7,5 & 8,0 & 8,3 & 8,5 & 8,4 & 8,2 \\
\hline 1 & 0,6 & 2,7 & 4,6 & 6,1 & 7,4 & 8,4 & 9,2 & 9,7 & 10,0 & 10,1 & 10,0 \\
\hline 1,2 & $-0,5$ & 2,0 & 4,2 & 6,1 & 7,6 & 8,9 & 9,8 & 10,5 & 10,8 & 11,0 & 10,9 \\
\hline 1,4 & $-1,7$ & 1,1 & 3,6 & 5,6 & 7,4 & 8,7 & 9,8 & 10,5 & 10,9 & 11,0 & 10,8 \\
\hline 1,6 & $-3,0$ & 0,1 & 2,7 & 4,9 & 6,6 & 8,0 & 9,1 & 9,7 & 10,0 & 10,0 & 9,6 \\
\hline 1,8 & $-4,2$ & $-1,1$ & 1,5 & 3,7 & 5,5 & 6,8 & 7,7 & 8,2 & 8,3 & 8,0 & 7,4 \\
\hline$V$ & 0 & 0,1 & 0,2 & 0,3 & 0,4 & 0,5 & 0,6 & 0,7 & 0,8 & 0,9 & 1 \\
\hline
\end{tabular}

The energy density of the studied system is in the range of $0,7 \leq V \leq 0,9$ and $1,2 \leq \delta \leq 1,4$, which is seen as in Fig. 5 and Tab. 2. The energy density of the studied system varies between 9,7 and 10,1 energy units around these points.

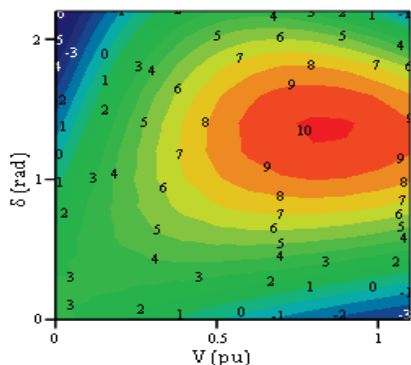

(a)

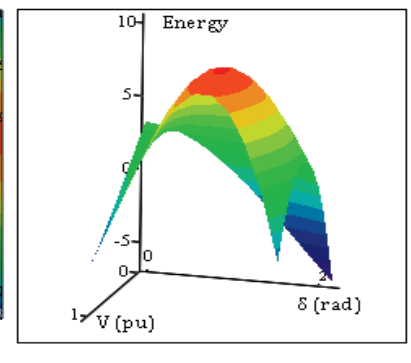

(b)
Figure 5 Stored energy for $\delta_{m}=0,4$ : (a) plot of the contours (b) $3 \mathrm{D}$ of the studied model

Table 2 Energy measurement for $\delta_{m}=0,4$

\begin{tabular}{|c|c|c|c|c|c|c|c|c|c|c|c|}
\hline$\delta$ & \multicolumn{10}{|c|}{ Energy measurement } \\
\hline 0 & 3,4 & 2,8 & 2,1 & 1,5 & 0,8 & 0,1 & $-0,6$ & $-1,2$ & $-1,8$ & $-2,4$ & $-2,9$ \\
\hline 0,2 & 3,2 & 3,2 & 3,0 & 2,8 & 2,4 & 2,1 & 1,6 & 1,2 & 0,7 & 0,2 & $-0,4$ \\
\hline 0,4 & 2,8 & 3,3 & 3,7 & 3,9 & 4,0 & 3,9 & 3,8 & 3,5 & 3,2 & 2,8 & 2,3 \\
\hline 0,6 & 2,3 & 3,3 & 4,2 & 4,8 & 5,3 & 5,6 & 5,7 & 5,7 & 5,5 & 5,2 & 4,8 \\
\hline 0,8 & 1,5 & 3,1 & 4,4 & 5,5 & 6,3 & 6,9 & 7,3 & 7,5 & 7,5 & 7,3 & 7,0 \\
\hline 1 & 0,6 & 2,7 & 4,4 & 5,8 & 7,0 & 7,9 & 8,5 & 8,9 & 9,0 & 9,0 & 8,7 \\
\hline 1,2 & $-0,4$ & 2,0 & 4,1 & 5,8 & 7,3 & 8,4 & 9,2 & 9,7 & 9,9 & 9,9 & 9,6 \\
\hline 1,4 & $-1,6$ & 1,2 & 3,5 & 5,5 & 7,1 & 8,4 & 9,3 & 9,9 & 10,1 & 10,1 & 9,7 \\
\hline 1,6 & $-2,8$ & 0,2 & 2,7 & 4,8 & 6,5 & 7,9 & 8,8 & 9,3 & 9,5 & 9,4 & 8,9 \\
\hline 1,8 & $-4,1$ & $-1,0$ & 1,7 & 3,8 & 5,5 & 6,8 & 7,6 & 8,1 & 8,1 & 7,8 & 7,0 \\
\hline$V$ & 0 & 0,1 & 0,2 & 0,3 & 0,4 & 0,5 & 0,6 & 0,7 & 0,8 & 0,9 & 1 \\
\hline
\end{tabular}

For $\delta_{m}=0,4 \mathrm{rad}$, Tab. 2 shows numerical values of the energy function for different load angles and different load voltages.

The energy density of the studied system is in the range of $0,6 \leq V \leq 1$ and $1,2 \leq \delta \leq 1,6$, which is seen as in Fig. 6 and Tab. 3. The energy density of the studied system varies between 7,3 and 8,9 energy units around these points.

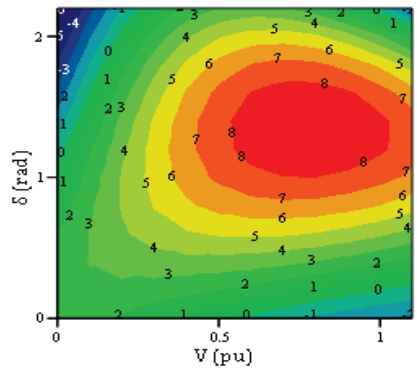

(a)

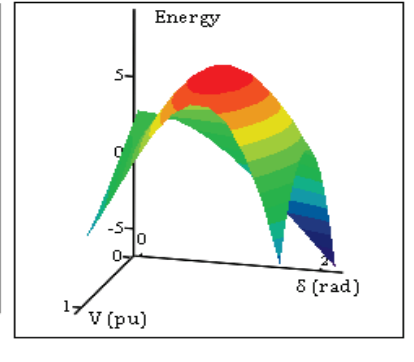

(b)
Figure 6 Stored energy for $\delta_{m}=0,8$ : (a) plot of the contours (b) 3D of the studied model 
Table 3 Energy measurement for $\delta_{m}=0,8$

\begin{tabular}{|c|c|c|c|c|c|c|c|c|c|c|c|}
\hline$\delta$ & \multicolumn{10}{|c|}{} \\
\hline 0 & 2,9 & 2,4 & 1,9 & 1,4 & 0,8 & 0,3 & $-0,3$ & $-0,8$ & $-1,3$ & $-1,7$ & $-2,1$ \\
\hline 0,2 & 2,8 & 2,8 & 2,7 & 2,6 & 2,3 & 2,0 & 1,6 & 1,2 & 0,8 & 0,3 & $-0,1$ \\
\hline 0,4 & 2,5 & 3,0 & 3,4 & 3,6 & 3,7 & 3,6 & 3,5 & 3,2 & 2,9 & 2,5 & 2,0 \\
\hline 0,6 & 2,0 & 3,1 & 3,9 & 4,5 & 4,9 & 5,1 & 5,2 & 5,1 & 4,9 & 4,5 & 4,1 \\
\hline 0,8 & 1,4 & 2,9 & 4,1 & 5,1 & 5,8 & 6,3 & 6,6 & 6,7 & 6,6 & 6,3 & 5,9 \\
\hline 1 & 0,5 & 2,5 & 4,1 & 5,4 & 6,5 & 7,2 & 7,7 & 7,9 & 7,9 & 7,7 & 7,2 \\
\hline 1,2 & $-0,4$ & 1,9 & 3,8 & 5,4 & 6,7 & 7,7 & 8,3 & 8,7 & 8,7 & 8,5 & 8,0 \\
\hline 1,4 & $-1,5$ & 1,1 & 3,3 & 5,2 & 6,6 & 7,7 & 8,4 & 8,8 & 8,9 & 8,7 & 8,1 \\
\hline 1,6 & $-2,7$ & 0,2 & 2,6 & 4,5 & 6,1 & 7,3 & 8,0 & 8,4 & 8,4 & 8,0 & 7,3 \\
\hline 1,8 & $-3,9$ & $-0,9$ & 1,6 & 3,6 & 5,2 & 6,3 & 7,0 & 7,3 & 7,1 & 6,6 & 5,6 \\
\hline$V$ & 0 & 0,1 & 0,2 & 0,3 & 0,4 & 0,5 & 0,6 & 0,7 & 0,8 & 0,9 & 1 \\
\hline
\end{tabular}

For $\delta_{m}=0,8 \mathrm{rad}$, Tab. 3 demonstrates numerical values of the energy function for different load angles and different load voltages.

The energy density of the studied system is in the range of $0,6 \leq V \leq 0,9$ and $1 \leq \delta \leq 1,6$, which is seen as in Fig. 7 and Tab. 4. The energy density of the studied system varies between 6,3 and 7,6 energy units around these points.

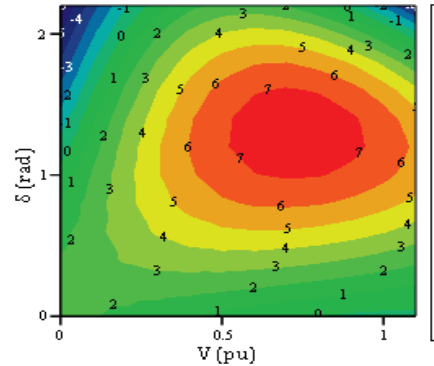

(a)

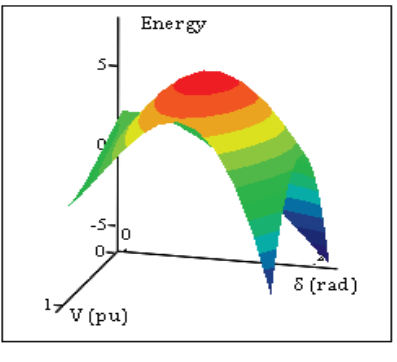

(b)
Figure 7 Stored energy for $\delta_{m}=1,2$ : (a) plot of the contours (b) 3D of the studied model

Table 4 Energy measurement for $\delta_{m}=1,2$

\begin{tabular}{|c|c|c|c|c|c|c|c|c|c|c|c|}
\hline$\delta$ & \multicolumn{10}{|c|}{ Energy measurement } \\
\hline 0 & 2,4 & 2,1 & 1,8 & 1,4 & 1,1 & 0,7 & 0,4 & 0,1 & $-0,1$ & $-0,3$ & $-0,4$ \\
\hline 0,2 & 2,3 & 2,4 & 2,5 & 2,5 & 2,4 & 2,2 & 2,0 & 1,8 & 1,5 & 1,2 & 1,0 \\
\hline 0,4 & 2,1 & 2,7 & 3,1 & 3,4 & 3,5 & 3,6 & 3,5 & 3,4 & 3,1 & 2,8 & 2,5 \\
\hline 0,6 & 1,7 & 2,7 & 3,5 & 4,1 & 4,6 & 4,8 & 4,9 & 4,9 & 4,7 & 4,4 & 3,9 \\
\hline 0,8 & 1,1 & 2,5 & 3,7 & 4,7 & 5,4 & 5,8 & 6,1 & 6,2 & 6,0 & 5,7 & 5,2 \\
\hline 1 & 0,3 & 2,2 & 3,7 & 4,9 & 5,9 & 6,5 & 6,9 & 7,1 & 7,0 & 6,7 & 6,1 \\
\hline 1,2 & $-0,6$ & 1,6 & 3,4 & 4,9 & 6,1 & 6,9 & 7,4 & 7,6 & 7,5 & 7,2 & 6,5 \\
\hline 1,4 & $-1,6$ & 0,9 & 2,9 & 4,6 & 5,9 & 6,8 & 7,4 & 7,6 & 7,5 & 7,1 & 6,3 \\
\hline 1,6 & $-2,7$ & 0,0 & 2,2 & 4,0 & 5,4 & 6,3 & 6,9 & 7,1 & 6,9 & 6,3 & 5,4 \\
\hline 1,8 & $-3,9$ & $-1,1$ & 1,3 & 3,1 & 4,5 & 5,4 & 5,9 & 5,9 & 5,6 & 4,8 & 3,6 \\
\hline$V$ & 0 & 0,1 & 0,2 & 0,3 & 0,4 & 0,5 & 0,6 & 0,7 & 0,8 & 0,9 & 1 \\
\hline
\end{tabular}

The numerical values of the energy function for different load angles and different load voltages for $\delta_{m}=1,2 \mathrm{rad}$ are indicated in Tab. 4 .

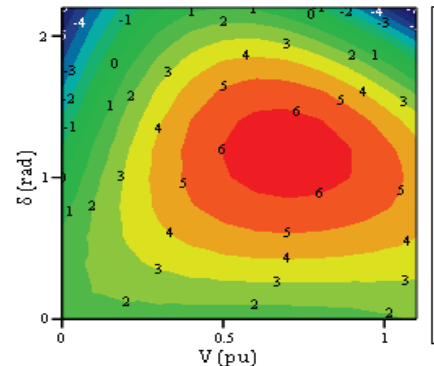

(a)

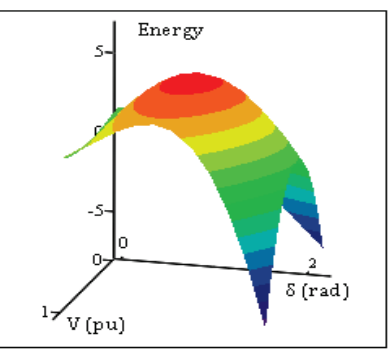

(b)
Figure 8 Stored energy for $\delta_{m}=1,6$ : (a) plot of the contours (b) 3D of the studied model
The energy density of the studied system is in the range of $0,5 \leq V \leq 0,8$ and $1 \leq \delta \leq 1,4$, which is seen as in Fig. 8 and Tab. 5. The energy density of the studied system varies between 5,8 and 6,5 energy units around these points.

Table 5 Energy measurement for $\delta_{m}=1,6$

\begin{tabular}{|c|c|c|c|c|c|c|c|c|c|c|c|}
\hline$\delta$ & \multicolumn{10}{|c|}{ Energy measurement } \\
\hline 0 & 1,7 & 1,7 & 1,6 & 1,5 & 1,4 & 1,4 & 1,3 & 1,3 & 1,4 & 1,5 & 1,7 \\
\hline 0,2 & 1,7 & 2,0 & 2,3 & 2,4 & 2,5 & 2,6 & 2,6 & 2,6 & 2,6 & 2,5 & 2,5 \\
\hline 0,4 & 1,5 & 2,2 & 2,8 & 3,2 & 3,5 & 3,7 & 3,8 & 3,8 & 3,8 & 3,6 & 3,4 \\
\hline 0,6 & 1,1 & 2,2 & 3,1 & 3,8 & 4,3 & 4,7 & 4,9 & 4,9 & 4,8 & 4,6 & 4,3 \\
\hline 0,8 & 0,6 & 2,1 & 3,3 & 4,2 & 4,9 & 5,4 & 5,7 & 5,8 & 5,7 & 5,4 & 5,0 \\
\hline 1 & $-0,1$ & 1,7 & 3,2 & 4,4 & 5,3 & 5,9 & 6,3 & 6,4 & 6,2 & 5,9 & 5,3 \\
\hline 1,2 & $-0,9$ & 1,2 & 2,9 & 4,3 & 5,3 & 6,0 & 6,4 & 6,5 & 6,4 & 5,9 & 5,2 \\
\hline 1,4 & $-1,8$ & 0,5 & 2,4 & 3,9 & 5,0 & 5,8 & 6,2 & 6,3 & 6,0 & 5,4 & 4,5 \\
\hline 1,6 & $-2,8$ & $-0,4$ & 1,6 & 3,2 & 4,4 & 5,2 & 5,5 & 5,5 & 5,1 & 4,3 & 3,2 \\
\hline 1,8 & $-3,9$ & $-1,4$ & 0,7 & 2,3 & 3,5 & 4,2 & 4,4 & 4,2 & 3,6 & 2,6 & 1,1 \\
\hline$V$ & 0 & 0,1 & 0,2 & 0,3 & 0,4 & 0,5 & 0,6 & 0,7 & 0,8 & 0,9 & 1 \\
\hline
\end{tabular}

For $\delta_{m}=1,6 \mathrm{rad}$., Tab. 5 shows numerical values of the energy function for different load angles and different load voltages.

\subsection{Energy function of the SMIB power system with SVC and numerical simulations}

The single-machine infinite-bus power system model with SVC differential equations above can be written again under the condition that the generator mechanical power is equivalent to the active load requirement $\left(P_{m}=\right.$ $\left.P_{1}\right)$.

$$
\begin{aligned}
& \dot{\omega}=-\frac{D}{M^{2}} M \omega-\frac{1}{M} a\left(\delta, \delta_{m}, V\right), \\
& \dot{\delta}_{m}=\frac{1}{M} M \omega, \\
& \dot{\delta}=-b\left(\delta, \delta_{m}, V\right), \\
& \dot{V}=-c\left(\delta, \delta_{m}, V\right),
\end{aligned}
$$

where,

$$
\begin{aligned}
& a\left(\delta, \delta_{m}, V\right)=-\left[P_{m}+E_{m} V Y_{m} \sin \left(\delta-\delta_{m}-\theta_{m}\right)+E_{m}{ }^{2} Y_{m} \sin \left(\theta_{m}\right)\right],(36) \\
& b\left(\delta, \delta_{m}, V\right)=-\frac{1}{K_{q w}}\left(-K_{q v 2} V^{2}-K_{q v} V+Q-Q_{0}+Q_{\mathrm{SVC}}-Q_{1}\right) \\
& c\left(\delta, \delta_{m}, V\right)=-\frac{1}{T K_{q w} K_{p v}}\left[K_{p w} K_{q v 2} V^{2}+\left(K_{p w} K q v \ldots-\right.\right. \\
& \left.\left.-K_{q w} K_{p v}\right) V+K_{p w}\left(Q_{0}-Q_{S V C}+Q_{1}-Q\right)-K_{q w}\left(P_{0}+P_{1}-P\right)\right] .
\end{aligned}
$$

The derivation of Lyapunov function for the singlemachine infinite-bus power system with SVC, Eqs. (32), (33), (34) and (35) could be determined as:

$$
\left[\begin{array}{c}
\dot{\delta}_{m} \\
\dot{\omega} \\
\dot{\delta} \\
\dot{V}
\end{array}\right]=\left[\begin{array}{cccc}
0 & -\frac{1}{M} & 0 & 0 \\
\frac{1}{M} & \frac{D}{M^{2}} & 0 & 0 \\
0 & 0 & 1 & 0 \\
0 & 0 & 0 & 1
\end{array}\right]\left[\begin{array}{c}
a\left(\delta_{m}, \delta, V\right) \\
M \omega \\
b\left(\delta_{m}, \delta, V\right) \\
c\left(\delta_{m}, \delta, V\right)
\end{array}\right] .
$$


The Eq. (39) for the model defined in Eqs. (13), (14), (15) and (16) is an alternative definition for dynamics of this model. For the $\left(\omega_{0}, \delta_{m 0}, \delta_{0}, V_{0}\right)$ 's equilibrium point, a candidate energy function, which is seen on the right of Eq. (39), $((4 \times 1)$ gradient matrix seen on the right of Eq. (39)) is obtained and therefore it can be used in Eq. (22). The candidate energy function can be written in Eq. (22) as:

$$
v\left(\omega, \delta_{m}, \delta, V\right)=\int_{\left(\omega_{0}, \delta_{m 0}, \delta_{0}, V_{0}\right)}^{\left(\omega, \delta_{m}, \delta, V\right)}\left[\begin{array}{c}
M \omega \\
a\left(\delta_{m}, \delta, V\right) \\
b\left(\delta_{m}, \delta, V\right) \\
c\left(\delta_{m}, \delta, V\right)
\end{array}\right]^{\mathrm{T}}\left[\begin{array}{c}
\mathrm{d} \omega \\
\mathrm{d} \delta_{m} \\
\mathrm{~d} \delta \\
\mathrm{d} V
\end{array}\right]
$$

If $a\left(\delta_{m}, \delta, V\right), b\left(\delta_{m}, \delta, V\right)$ and $c\left(\delta_{m}, \delta, V\right)$ are replaced on Eq. (40), energy function of the single-machine infinite-bus power system with SVC is obtained [23]. The equilibrium point is $\left(\omega^{*}, \delta_{m}{ }^{*}, \delta^{*}, V^{*}\right)=(0,0 ; 0,7855 ; 0,2$; $1)$.

The generator rotor angle will be changed, beginning with zero and will be increased to 1,6 by 0,4 rise each turn in order to observe the system stability. The numerical simulations of the single-machine infinite-bus power system with SVC are carried out by using Mathcad [24].

The energy density of the studied system is in the range of $0,8 \leq V \leq 1$ and $1,2 \leq \delta \leq 1,4$, which is seen as in Fig. 9 and Tab. 6. The energy density of the studied system varies between 11,8 and 12,4 energy units around these points.

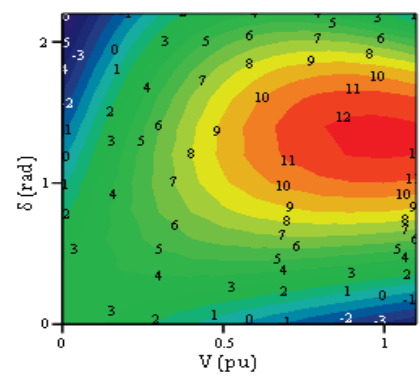

(a)

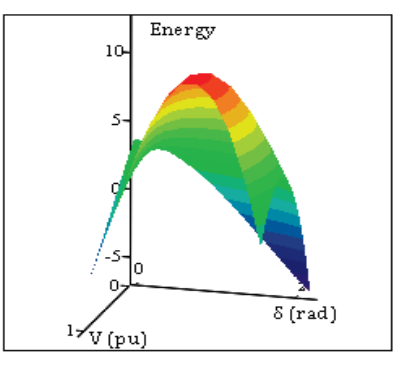

(b)
Figure 9 Stored energy for $\delta_{m}=0$ : (a) plot of the contours (b) 3D of the studied model with SVC

Table 6 Energy measurement for $\delta_{m}=0$

\begin{tabular}{|c|c|c|c|c|c|c|c|c|c|c|c|}
\hline$\delta$ & \multicolumn{10}{|c|}{ Energy measurement } \\
\hline 0 & 3,9 & 3,2 & 2,5 & 1,8 & 1,1 & 0,3 & $-0,4$ & $-1,2$ & $-1,9$ & $-2,6$ & $-3,2$ \\
\hline 0,2 & 3,6 & 3,6 & 3,4 & 3,2 & 2,9 & 2,5 & 2,1 & 1,6 & 1,1 & 0,6 & 0,1 \\
\hline 0,4 & 3,2 & 3,7 & 4,1 & 4,4 & 4,6 & 4,6 & 4,5 & 4,3 & 4,1 & 3,8 & 3,4 \\
\hline 0,6 & 2,5 & 3,7 & 4,6 & 5,4 & 6,0 & 6,4 & 6,7 & 6,8 & 6,8 & 6,7 & 6,4 \\
\hline 0,8 & 1,7 & 3,4 & 4,8 & 6,0 & 7,0 & 7,8 & 8,4 & 8,8 & 9,1 & 9,1 & 9,1 \\
\hline 1 & 0,7 & 2,9 & 4,8 & 6,4 & 7,7 & 8,8 & 9,7 & 10,3 & 10,8 & 11,0 & 11,0 \\
\hline 1,2 & $-0,4$ & 2,2 & 4,4 & 6,4 & 8,0 & 9,3 & 10,4 & 11,2 & 11,8 & 12,1 & 12,2 \\
\hline 1,4 & $-1,5$ & 1,3 & 3,8 & 6,0 & 7,8 & 9,3 & 10,5 & 11,4 & 12,0 & 12,3 & 12,4 \\
\hline 1,6 & $-2,8$ & 0,3 & 2,9 & 5,2 & 7,1 & 8,7 & 9,9 & 10,7 & 11,3 & 11,5 & 11,5 \\
\hline 1,8 & $-4,1$ & $-0,9$ & 1,8 & 4,1 & 5,9 & 7,4 & 8,6 & 9,3 & 9,7 & 9,8 & 9,5 \\
\hline$V$ & 0 & 0,1 & 0,2 & 0,3 & 0,4 & 0,5 & 0,6 & 0,7 & 0,8 & 0,9 & 1 \\
\hline
\end{tabular}

For $\delta_{m}=0 \mathrm{rad}$, Tab. 6 shows numerical values of the energy function for different load angles and different load voltages.

The energy density of the studied system is in the range of $0,8 \leq V \leq 1$ and $1,2 \leq \delta \leq 1,4$, which is seen as in Fig. 10 and Tab. 7. The energy density of the studied system varies between 10,9 and 11,4 energy units around these points.

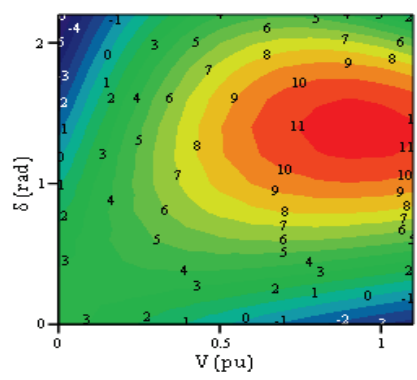

(a)

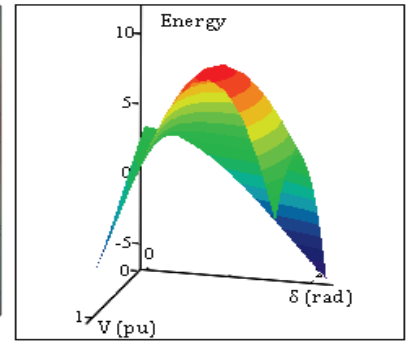

(b)
Figure 10 Stored energy for $\delta_{m}=0,4$ : (a) plot of the contours (b) 3D of the studied model with SVC

Table 7 Energy measurement for $\delta_{m}=0,4$

\begin{tabular}{|c|c|c|c|c|c|c|c|c|c|c|c|}
\hline$\delta$ & \multicolumn{10}{|c|}{ Energy measurement } \\
\hline 0 & 3,6 & 2,9 & 2,3 & 1,6 & 0,9 & 0,2 & $-0,5$ & $-1,2$ & $-1,9$ & $-2,6$ & $-3,1$ \\
\hline 0,2 & 3,4 & 3,3 & 3,2 & 2,9 & 2,6 & 2,2 & 1,8 & 1,3 & 0,8 & 0,2 & $-0,3$ \\
\hline 0,4 & 3,0 & 3,5 & 3,9 & 4,1 & 4,2 & 4,1 & 4,0 & 3,8 & 3,4 & 3,0 & 2,6 \\
\hline 0,6 & 2,4 & 3,5 & 4,4 & 5,0 & 5,5 & 5,8 & 6,0 & 6,0 & 5,9 & 5,7 & 5,4 \\
\hline 0,8 & 1,7 & 3,3 & 4,6 & 5,7 & 6,6 & 7,3 & 7,7 & 8,0 & 8,1 & 8,0 & 7,8 \\
\hline 1 & 0,8 & 2,8 & 4,6 & 6,1 & 7,3 & 8,3 & 9,0 & 9,5 & 9,8 & 9,9 & 9,7 \\
\hline 1,2 & $-0,3$ & 2,2 & 4,3 & 6,1 & 7,6 & 8,9 & 9,8 & 10,5 & 10,9 & 11,0 & 11,0 \\
\hline 1,4 & $-1,4$ & 1,4 & 3,8 & 5,8 & 7,5 & 8,9 & 10,0 & 10,8 & 11,2 & 11,4 & 11,3 \\
\hline 1,6 & $-2,6$ & 0,4 & 3,0 & 5,2 & 7,0 & 8,5 & 9,6 & 10,4 & 10,8 & 10,9 & 10,8 \\
\hline 1,8 & $-3,9$ & $-0,8$ & 1,9 & 4,2 & 6,0 & 7,5 & 8,5 & 9,2 & 9,5 & 9,5 & 9,1 \\
\hline$V$ & 0 & 0,1 & 0,2 & 0,3 & 0,4 & 0,5 & 0,6 & 0,7 & 0,8 & 0,9 & 1 \\
\hline
\end{tabular}

The numerical values of the energy function for different load angles and different load voltages for $\delta_{m}=0,4 \mathrm{rad}$ are shown in Tab. 7 .

The energy density of the studied system is in the range of $0,8 \leq V \leq 0,9$ and $1,2 \leq \delta \leq 1,6$, which is seen as in Fig. 11 and Tab. 8. The energy density of the studied system varies between 9,7 and 10,1 energy units around these points.

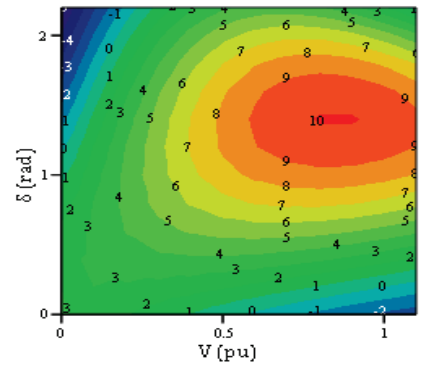

(a)

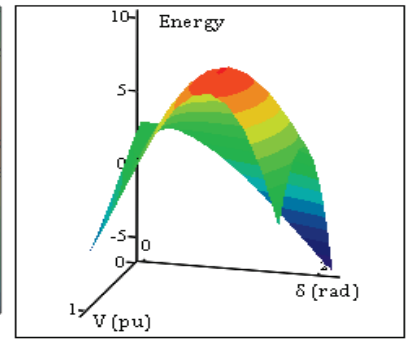

(b)
Figure 11 Stored energy for $\delta_{m}=0,8$ : (a) plot of the contours (b) 3D of the studied model with SVC

Table 8 Energy measurement for $\delta_{m}=0,8$

\begin{tabular}{|c|c|c|c|c|c|c|c|c|c|c|c|}
\hline$\delta$ & \multicolumn{10}{|c|}{ Energy measurement } \\
\hline 0 & 3,1 & 2,6 & 2,1 & 1,5 & 1,0 & 0,4 & $-0,2$ & $-0,7$ & $-1,3$ & $-1,7$ & $-2,2$ \\
\hline 0,2 & 3,0 & 3,0 & 2,9 & 2,7 & 2,5 & 2,2 & 1,8 & 1,4 & 1,0 & 0,5 & 0,1 \\
\hline 0,4 & 2,7 & 3,2 & 3,6 & 3,8 & 3,9 & 3,9 & 3,8 & 3,5 & 3,2 & 2,9 & 2,4 \\
\hline 0,6 & 2,2 & 3,2 & 4,1 & 4,7 & 5,1 & 5,4 & 5,6 & 5,5 & 5,4 & 5,1 & 4,7 \\
\hline 0,8 & 1,6 & 3,1 & 4,3 & 5,3 & 6,1 & 6,7 & 7,1 & 7,3 & 7,3 & 7,1 & 6,8 \\
\hline 1 & 0,7 & 2,7 & 4,3 & 5,7 & 6,8 & 7,6 & 8,2 & 8,6 & 8,8 & 8,7 & 8,5 \\
\hline 1,2 & $-0,3$ & 2,1 & 4,1 & 5,7 & 7,1 & 8,2 & 9,0 & 9,5 & 9,7 & 9,7 & 9,5 \\
\hline 1,4 & $-1,3$ & 1,3 & 3,6 & 5,5 & 7,0 & 8,3 & 9,2 & 9,8 & 10,1 & 10,1 & 9,8 \\
\hline 1,6 & $-2,5$ & 0,3 & 2,8 & 4,9 & 6,6 & 7,9 & 8,8 & 9,4 & 9,7 & 9,7 & 9,3 \\
\hline 1,8 & $-3,7$ & $-0,7$ & 1,8 & 4,0 & 5,7 & 7,0 & 7,9 & 8,5 & 8,6 & 8,4 & 7,9 \\
\hline$V$ & 0 & 0,1 & 0,2 & 0,3 & 0,4 & 0,5 & 0,6 & 0,7 & 0,8 & 0,9 & 1 \\
\hline
\end{tabular}

For $\delta_{m}=0,8 \mathrm{rad}$, Tab. 8 shows numerical values of the energy function for different load angles and different load voltages.

The energy density of the studied system is in the range of $0,6 \leq V \leq 1$ and $1,2 \leq \delta \leq 1,6$, which is seen as in 
Fig. 12 and Tab. 9. The energy density of the studied system varies between 7,3 and 8,7 energy units around these points.

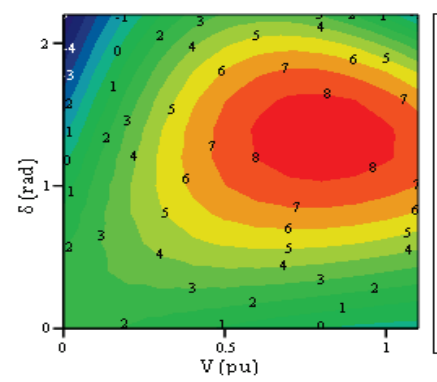

(a)

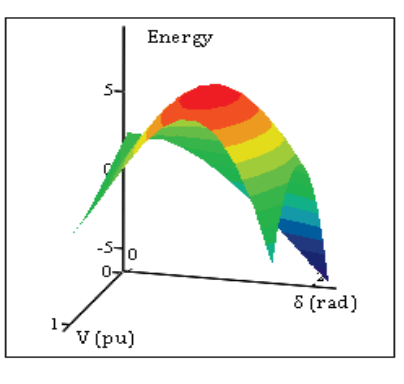

(b)
Figure 12 Stored energy for $\delta_{m}=1,2$ : (a) plot of the contours (b) 3D of the studied model with SVC

Table 9 Energy measurement for $\delta_{m}=1,2$

\begin{tabular}{|c|c|c|c|c|c|c|c|c|c|c|c|}
\hline$\delta$ & \multicolumn{10}{|c|}{ Energy measurement } \\
\hline 0 & 2,5 & 2,2 & 1,9 & 1,6 & 1,2 & 0,9 & 0,5 & 0,2 & $-0,1$ & $-0,3$ & $-0,5$ \\
\hline 0,2 & 2,5 & 2,6 & 2,7 & 2,6 & 2,5 & 2,4 & 2,2 & 1,9 & 1,7 & 1,4 & 1,1 \\
\hline 0,4 & 2,2 & 2,8 & 3,3 & 3,6 & 3,8 & 3,8 & 3,8 & 3,7 & 3,5 & 3,2 & 2,9 \\
\hline 0,6 & 1,8 & 2,9 & 3,7 & 4,3 & 4,8 & 5,1 & 5,3 & 5,3 & 5,2 & 5,0 & 4,6 \\
\hline 0,8 & 1,2 & 2,7 & 3,9 & 4,9 & 5,7 & 6,2 & 6,5 & 6,7 & 6,7 & 6,5 & 6,2 \\
\hline 1 & 0,5 & 2,3 & 3,9 & 5,2 & 6,2 & 7,0 & 7,5 & 7,8 & 7,8 & 7,7 & 7,3 \\
\hline 1,2 & $-0,4$ & 1,8 & 3,6 & 5,2 & 6,4 & 7,4 & 8,0 & 8,4 & 8,5 & 8,4 & 8,0 \\
\hline 1,4 & $-1,4$ & 1,1 & 3,2 & 4,9 & 6,3 & 7,4 & 8,1 & 8,5 & 8,7 & 8,5 & 8,0 \\
\hline 1,6 & $-2,5$ & 0,2 & 2,4 & 4,3 & 5,8 & 7,0 & 7,7 & 8,1 & 8,2 & 7,9 & 7,3 \\
\hline 1,8 & $-3,7$ & $-0,9$ & 1,5 & 3,5 & 5,0 & 6,1 & 6,8 & 7,1 & 7,1 & 6,6 & 5,9 \\
\hline$V$ & 0 & 0,1 & 0,2 & 0,3 & 0,4 & 0,5 & 0,6 & 0,7 & 0,8 & 0,9 & 1 \\
\hline
\end{tabular}

For $\delta_{m}=1,2 \mathrm{rad}$, Tab. 9 shows numerical values of the energy function for different load angles and different load voltages.

The energy density of the studied system is in the range of $0,6 \leq V \leq 0,9$ and $1 \leq \delta \leq 1,4$, which is seen as in Fig. 13 and Tab. 10. The energy density of the studied system varies between 6,8 and 7,4 energy units around these points.

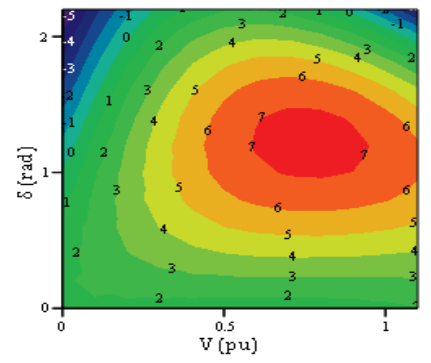

(a)

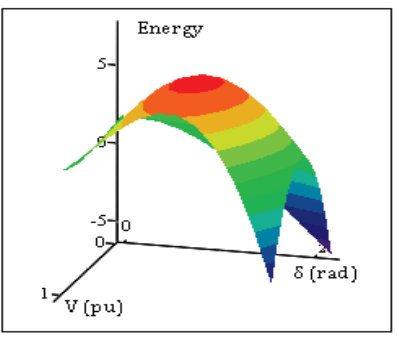

(b)
Figure 13 Stored energy for $\delta_{m}=1,6$ : (a) plot of the contours (b) 3D of the studied model with SVC

Table 10 Energy measurement for $\delta_{m}=1,6$

\begin{tabular}{|c|c|c|c|c|c|c|c|c|c|c|c|}
\hline$\delta$ & \multicolumn{10}{|c|}{ Energy measurement } \\
\hline 0 & 1,9 & 1,9 & 1,8 & 1,7 & 1,6 & 1,5 & 1,4 & 1,4 & 1,4 & 1,5 & 1,6 \\
\hline 0,2 & 1,9 & 2,2 & 2,4 & 2,6 & 2,7 & 2,8 & 2,8 & 2,8 & 2,7 & 2,7 & 2,7 \\
\hline 0,4 & 1,7 & 2,4 & 3,0 & 3,4 & 3,7 & 4,0 & 4,1 & 4,1 & 4,1 & 4,0 & 3,9 \\
\hline 0,6 & 1,3 & 2,4 & 3,3 & 4,0 & 4,6 & 5,0 & 5,2 & 5,4 & 5,3 & 5,2 & 5,0 \\
\hline 0,8 & 0,8 & 2,2 & 3,5 & 4,5 & 5,2 & 5,8 & 6,2 & 6,4 & 6,4 & 6,2 & 5,9 \\
\hline 1 & 0,1 & 1,9 & 3,4 & 4,6 & 5,6 & 6,3 & 6,8 & 7,0 & 7,1 & 6,9 & 6,5 \\
\hline 1,2 & $-0,7$ & 1,4 & 3,1 & 4,6 & 5,7 & 6,5 & 7,1 & 7,3 & 7,4 & 7,1 & 6,6 \\
\hline 1,4 & $-1,7$ & 0,7 & 2,6 & 4,2 & 5,4 & 6,3 & 6,9 & 7,2 & 7,2 & 6,8 & 6,2 \\
\hline 1,6 & $-2,7$ & $-0,2$ & 1,9 & 3,6 & 4,9 & 5,8 & 6,3 & 6,5 & 6,4 & 5,9 & 5,1 \\
\hline 1,8 & $-3,8$ & $-1,2$ & 1,0 & 2,7 & 4,0 & 4,8 & 5,3 & 5,4 & 5,1 & 4,4 & 3,4 \\
\hline$V$ & 0 & 0,1 & 0,2 & 0,3 & 0,4 & 0,5 & 0,6 & 0,7 & 0,8 & 0,9 & 1 \\
\hline
\end{tabular}

For $\delta_{m}=1,6 \mathrm{rad}$, Tab. 10 demonstrates numerical values of the energy function for different load angles and different load voltages.

After all of these simulations, it is observed that the value of the whole energy density decreased. This energy density decrease is an indicator of movement of operating point near the edge of instability region. In the SMIB power system without SVC simulation for $\delta_{m}=0$, while $\delta=1,4 \mathrm{rad}$ and $V=0,9 \mathrm{pu}$, maximum energy level was 11 energy units (see Fig. 4 and Tab. 1). However, in the SMIB power system without SVC simulation for $\delta_{m}=1,6$, energy level was 5,4 energy units even the same value of $\delta$ and V (see Fig. 8 and Tab. 5). It is also observed clearly that any changes in load will continue to decrease the level of energy density to low values, and it is even possible to see negative values. The level of energy density is one of the most important reasons that SVC is enhance. When SVC is not considered, maximum energy level is 11 energy units (see Fig. 4 and Tab. 1). When the SMIB power system with SVC is considered, maximum energy level is increased to 12,4 energy units (see Fig. 9 and Tab. 6).

\section{Conclusion}

In this paper, the construction of a Lyapunov (energy) function for the SMIB power system model with and without SVC by using the variable gradient method based on Lyapunov's second method has been considered. The variable gradient method is used to construct a Lyapunov function to show voltage stability of studied power systems. In above studies the effect of SVC is presented and the comparison between simulation results is done. The results obtained show that stability margins of power system are significantly extended with the inclusion of SVC. In addition, it has been demonstrated by numerical simulations that any changes in load result in remarkable changes in the level of energy density. As a final remark, this paper indicated that a more optimal energy function, which can clearly show the critical load angles gained on the levels of energy density, related to the representations of system works in the different levels and load voltages, can be achieved. It is hoped that this study will help to the construction of a suitable energy function for the problem of power system stability.

\section{Appendix}

Power system parameters considered for simulation, except those for SVC are taken from [8] and are given below. All values are in per unit except for angles, which are in radian.

Load parameter values:

$K_{p w}=0,4 ; K_{p v}=0,3 ; K_{q w}=-0,03 ; K_{q v}=-2,8 ; K_{q v 2}=2,1$; $T=8,5 ; P_{0}=0,6 ; Q_{0}=1,3 ; P_{1}=0,0 ; Q_{1}=0,0$.

Network and generator parameter values:

$Y_{0}=20 ; \theta_{0}=-5,0 ; E_{0}=1,0 ; C=12,0 ; Y_{0}{ }^{\prime}=8,0 ; \theta_{0}{ }^{\prime}=$ $-12,0 ; E_{0}{ }^{\prime}=2,5 ; Y_{\mathrm{m}}=5,0 ; \theta_{\mathrm{m}}=-5,0 ; E_{\mathrm{m}}=1,0 ; P_{\mathrm{m}}=1,0$; $D=0,05 ; M=0,3$. 
SVC parameter values:

$K_{\mathrm{SVC}}=2,0 ; T_{\mathrm{SVC}}=0,01 ; B_{\mathrm{LIMIT}}=1,0$

\section{References}

[1] Kundur, P. Power System Stability and Control. McGrawHill, Toronto, 1994

[2] Garcia-Kasusky, R.; Torres-Lucio, D.; Fuerte-Esquivel, C.Assessment of the SVC's Effect on Nonlinear Instabilities and Voltage Collapse in Electric Power Systems. // Proceedings of the 2003 IEEE Power Engineering Society General Meeting / Toronto, 2003, pp. 2659-2666

[3] Saad, M. S.; Hassouneh, M. A.; Abed E. H.; Edris A. A. Delaying Instability and Voltage Collapse in Power Systems using SVCs with Washout Filter-Aided Feedback. // Proceedings of the 2005 American Control Conference / Portland, 2005, pp. 4357-4362. DOI: 10.1109/acc.2005.1470665

[4] Liaw, D. C.; Chang, S. T.; Huang, Y. H.; Huang, J. T.; Yenn, T. C.Load Voltage Tracking of Electric Power Systems by using Backstepping Design. // ICROS-SICE International Joint Conference / Fukuoka City, 2009, pp. 608-613.

[5] Padma Subramanian, D.; Kumudini Devim R. P.; Saravanaselvan, R. A New Algorithm for Analysis of SVC's Impact on Bifurcations, Chaos and Voltage Collapse in Power Systems. // International Journal of Electrical Power and Energy Systems. 33, (2011), pp. 1194-1202. DOI: 10.1016/j.jijepes.2011.01.033

[6] Blasina, M.; Komen, V.; Cucic, R. Voltage Control and Compensation of Reactive Power by SVC Devices. // Eng. Rev. 30, 2(2010), pp. 47-58.

[7] Komen, V.; Blasina, M.; Cucic, R. Research on the Power Grid Operation Improvement by Static VAR Compensators // Technical Gazette. 19, 1(2012), pp. 57-64.

[8] Chiang, H. D.; Dobson, I.; Thomas, R. J.; Thorp, J. S.;Fekih-Ahmed L. On Voltage Collapse in Electric Power Systems. // IEEE Transactions on Power Systems. 5, (1990), pp. 601-611. DOI: 10.1109/59.54571

[9] Hiskens, I. A.; Davy, R. J. Lyapunov Function Analysis of Power Systems with Dynamic Loads. // Proceedings of the 35th Conference on Decision and Control / Kobe, 1996, pp. 3870-3875. DOI: 10.1109/CDC.1996.577267

[10] Chen, Y.; Zhou, K. A New Energy Function Based Power System Stability Control Scheme using Real-Time Data. // Proceedings of the International Conference on Power System Technology / Perth, 2000, pp. 163-168.

[11] Jurado, F.; Carpio, J. Energy Functions Analysis in Voltage Collapse. // European Transactions on Electrical Power. 11, 4(2001), pp. 235-240. DOI: 10.1002/etep.4450110404

[12] Gabrijel, U.; Mihalic, R. Direct Methods for Transient Stability Assessment in Power Systems Comprising Controllable Series Devices. // IEEE Transactions on Power Systems. 17, 4(2002), pp. 1116-1122. DOI: 10.1109/TPWRS.2002.805015

[13] Ishigama, A.; Sakaguchi, H.; Takashima, J.; Suzaki, Sh. Construction of Lyapunov Function for Power System Based on Solving Linear Matrix Inequality. // Electrical Engineering in Japan. 158, 4(2007), pp. 41-50. DOI: 10.1002/eej.20328

[14] Anghel, M.; Milano, F.; Papachristodoulou A.Algorithmic Construction of Lyapunov Functions for Power System Stability Analysis. // IEEE Transactions on Circuits and Systems I: Regular Papers. 60, 9(2013), pp. 1-14. DOl: 10.1109/TCSI.2013.2246233

[15] Zubov, V. I. Methods of A. M. Lyapunov and Their Application. P. Noordhoff, Groningen, 1964.
[16] Szegö, G. P. On a New Partial Differential Equation for the Stability Analysis of Time Invariant Control Systems. // Journal of the Society for Industrial and Applied Mathematics Series A Control. 1, 1(1962), pp. 63-75. DOI: 10.1137/0301005

[17] Ingwerson, D. R. A Modified Lyapunov Method for Nonlinear Stability Analysis. // IRE Transactions on Automatic Control. AC-6, (1961), pp. 199-210. DOI: 10.1109/TAC.1961.1105195

[18] Krasovskii, N. N. Problems of the Theory of Stability of Motion. CA: Stanford University Press, Stanford, 1959.

[19] Schultz, D. G.; Gibson J. E. The Variable Gradient Method for Generating Lyapunov Functions. // Transactions on American Institute of Electrical Engineers. 81, 4(1962), pp. 203-210.

[20] Slotine, J. J. E.; Li, W. Applied Nonlinear Control. Prentice Hall, New Jersey, 1991.

[21] Nikravesh, S. K. Y. Nonlinear Systems Stability Analysis: Lyapunov-Based Approach. CRC Press, 2013. DOI: 10.1201/b13731

[22] DeMarco, C. L. Approximating Power System Dynamics and Energy Functions by Quasi-Gradient Models. // IEEE International Symposium on Circuits and Systems / Portland, 1989, pp. 1966-1969. DOl: 10.1109/ISCAS.1989.100756

[23] Çifci, A. Voltage Stability Analysis Based Energy Function of Electrical Power Systems Incorporating FACTS Devices. Department of Electrical-Electronics Engineering, Sakarya University, Sakarya, PhD Thesis, 2015. (Text in Turkish)

[24] MATHCAD User's Guide. Parametric Technology Corporation, 2007.

\section{Authors' addresses}

Ahmet Çifci, Dr., Asst. Prof. (Corresponding Author)

Faculty of Engineering and Architecture,

Mehmet Akif Ersoy University,

Istiklal Campus, 15030 Burdur, Turkey

E-mail: acifci@mehmetakif.edu.tr

Yulmaz Uyaroğlu, Dr., Assoc. Prof.

Faculty of Engineering, Sakarya University, Esentepe Campus, 54187 Sakarya, Turkey

E-mail: uyaroglu@sakarya.edu.tr 